\title{
Glomerular Filtration and Tubular Reabsorption of Albumin in Preproteinuric and Proteinuric Diabetic Rats
}

\author{
Bryan J. Tucker, Ruth Rasch, * and Roland C. Blantz \\ Department of Medicine, University of California, San Diego School of Medicine, La Jolla, California 92093 \\ and Division of Nephrology-Hypertension, Veterans Affairs Medical Center, San Diego, California 92161; \\ and * Department of Cell Biology, Institute of Anatomy, University of Aarhus, Aarhus, Denmark
}

\begin{abstract}
Microalbuminuria (26-250 $\mathrm{mg} / \mathrm{d}$ ) is considered to be an indicator of incipient diabetic nephropathy in humans in insulin-dependent diabetes (IDD). However, before microalbuminuria is observed, glomerular alterations, such as glycosylation of the glomerular basement membrane and glomerular hyperfiltration, in IDD may result in increased filtration of albumin before any observed increase in albumin excretion. Glomerular and tubular albumin kinetics were examined in streptozotocin (65 $\mathrm{mg} / \mathrm{kg}$ body wt, i.v.) diabetic, Munich-Wistar rats at 7-10 (untreated) and 50-70 d (poorly controlled with small doses of insulin) after the onset of diabetes and compared with nondiabetic controls. Additional rats in each condition received acute lysine treatment to prevent tubular protein reabsorption. Urinary albumin excretion and nonvascular albumin distribution volumes were measured in the renal cortex and compared with morphometric measurements of interstitial space and the proximal tubule to assess intracellular uptake of albumin in the proximal tubule. Urinary albumin excretion under anesthesia was not different in 7-10-d IDD versus controls (19 \pm 3 vs. $20 \pm 3 \mu \mathrm{g} / \mathrm{min})$ but increased in the 50-70-d IDD $(118 \pm 13 \mu \mathrm{g} /$ $\min , P<0.05)$. Lysine treatment resulted in increased albumin excretion compared with respective nontreatment in 7-10-d IDD $(67 \pm 10 \mu \mathrm{g} / \mathrm{min}, P<0.05)$ but not in controls $(30 \pm 6$ $\mu \mathrm{g} / \mathrm{min})$ or in 50-70-d IDD $(126 \pm 11 \mu \mathrm{g} / \mathrm{min})$. Glomerular filtration rate was increased both in 7-10-d IDD $(2.7 \pm 0.1 \mathrm{ml} /$ $\min , P<0.05)$ and in 50-70-d IDD $(2.6 \pm 0.1 \mathrm{ml} / \mathrm{min}, P$ $<0.05)$ compared with control $(2.2 \pm 0.1 \mathrm{ml} / \mathrm{min})$. Calculated urinary space albumin concentrations increased early in IDD with $2.5 \pm 0.4 \mathrm{mg} \%$ in 7-10-d IDD and $4.9 \pm 0.6 \mathrm{mg} \%$ in 50-70-d IDD compared with control $(1.4 \pm 0.3 \mathrm{mg} \%)$. The increase in filtration of albumin is in excess of that attributable to hyperfiltration before increased albumin excretion early in diabetes. In 50-70-d IDD, absolute tubular reabsorption of albumin is decreased, correlating to the decrease in brush border height of the proximal tubule. (J. Clin. Invest. 1993. 92:686-694.) Key words: transcapillary albumin escape rate $\bullet$ urinary albumin
\end{abstract}

Portions of these studies were presented at the annual meetings of the American Society of Nephrology, Baltimore, MD, December 1991 and at the European Association for the Study of Diabetes, Prague, Czechoslovakia, September 1992.

Address correspondence to Bryan J. Tucker, Nephrology Research, 9151, University of California, San Diego, La Jolla, CA 92093-9151.

Received for publication 21 May 1992 and in revised form 5 March 1993.

J. Clin. Invest.

(c) The American Society for Clinical Investigation, Inc.

0021-9738/93/08/0686/09 \$2.00

Volume 92, August 1993, 686-694 excretion • blood volume $\bullet$ morphometry $\bullet$ protein reabsorption • STZ diabetes

\section{Introduction}

The early phases of insulin-dependent diabetes (IDD) ${ }^{1}$ are not associated with significant increased urinary albumin excretion. Before the onset of microalbuminuria there is a time period, which may persist for years, in the course of IDD in humans in which renal hypertrophy and glomerular hyperfiltration are observed with no other indicators of glomerular pathology. However, several studies have demonstrated increased systemic transcapillary albumin escape, both in humans early in IDD (1) and in rats shortly after the onset of experimental diabetes (2). Although the glomerular capillary bed differs from capillaries in skeletal muscle and other vascular beds, it is possible that similar alterations in the glomerular basement membrane or the protein filtration barrier have occurred but are masked by the inherent protein reabsorptive capacity of the proximal tubule. In addition, studies by Vittinghus and Mogensen (3) demonstrated that protein excretion during exercise is significantly increased in early nonproteinuric diabetics compared with normal healthy nondiabetics, when stressed by the same exercise protocol. These studies would suggest that early alterations in the glomerulus produce increased filtration of macromolecules. This also implies early reversibility of this process. Whether this potential alteration in early glomerular macromolecular filtration is present in unstressed conditions is unknown.

The importance of this issue is that a number of alterations occur early in the kidney after onset of diabetes and well before the observance of microalbuminuria. These early alterations include glomerular hyperfiltration (4), hypertrophy and hyperplasia $(5)$, glycosylation of membrane proteins $(6,7)$ and circulating albumin (8), and changes in the composition of the glomerular extracellular matrix material (9). All these alterations have been purported to increase glomerular filtration of albumin. However, the observation of increased protein excretion may occur at some period significantly after pathological alterations in the glomerulus. It is possible that changes in the glomerulus and specifically the filtration barrier for macromolecules permit albumin filtration to increase early in the course of IDD but the magnitude of this increase has not been detected because of the inherent capacity of the proximal tubule to reabsorb protein. This time line dissociation between patho-

1. Abbreviations used in this paper: $\mathrm{A} / \mathrm{G}$, albumin/globulin ratio; $B / G$, blood glucose concentrations; $B V$, blood volume; $C_{A}$, systemic protein concentration; Hct, hematocrit; IDD, insulin-dependent diabetes; $\mathrm{KW}$, kidney weight; $\mathrm{TER}_{\mathrm{abb}}$, systemic transcapillary albumin escape rate; $\mathrm{Vd}_{\mathrm{alb}}$, nonvascular albumin distribution. 
physiological alterations in the kidney and the increase in urinary protein excretion increases the difficulty in the specific determination of the mechanism or mechanisms responsible for increased albumin excretion.

The present study was designed to examine the alterations in glomerular albumin filtration and tubular reabsorption of albumin at two time points in diabetes: $(a)$ early after the onset of diabetes when renal morphological alterations have not been established and $(b)$ in established moderately hyperglycemic experimental diabetes. Streptozotocin was administered to induce experimental diabetes in Munich-Wistar rats and glomerular filtration and tubular reabsorption of albumin was examined at 7-10 and 50-70 d after the onset of diabetes. Lysine was infused to prevent tubular reabsorption of protein in separate groups of rats (nondiabetic, 7-10-, and 50-70-d diabetics) to determine glomerular filtration of albumin and net albumin excretion. In addition, systemic transcapillary albumin escape rates and renal cortical distribution volumes of albumin were also obtained.

\section{Methods}

All experiments were performed on male Munich-Wistar rats. The rats (Simonsen Laboratories, Gilroy, CA) were housed at the Veterans Affairs Medical, Veterinary Medical Unit. All rats were allowed access to food and water ad lib until the time of the radioisotopic or morphological studies.

\section{Albumin filtration and reabsorption studies}

On the morning of the study, the rats were anesthetized with a long-acting thiobarbituate, Inactin $(100 \mathrm{mg} / \mathrm{kg}$ body wt, i.p.; Andrew Lockwood Associates, Ann Arbor, MI). A tracheostomy was performed (PE-240), and PE-50 catheters were placed in the left jugular vein, left femoral artery, and bladder. Care was taken to ensure closure of all surgical access points and, after placement of the bladder catheter, the peritoneal opening was sutured closed (4-0 Dexon; Burlingame Surgical, San Diego, CA) to prevent fluid and protein losses from this access. Body temperature was regulated on a heated table with a servo-controlled heating unit. After completion of the placement of the catheters, blood $(<100 \mu \mathrm{l})$ was drawn for measurement of initial hematocrit, plasma protein concentration using the method of Lowry et al. (10), and blood glucose concentration (Ames Glucometer; Miles Laboratories Inc., Elkhart, IN). Once the initial blood withdrawal was completed, $1 \mathrm{ml}$ of blood was removed and centrifuged. When the centrifugation was completed, the plasma was reinfused into the animal and the remaining erythrocytes were labeled with ${ }^{51} \mathrm{Cr}(\approx 15 \mu \mathrm{Ci}$ per rat $)$ as described by Sterling (11) and Sterling and Gray (12) for measurement of blood volumes (both systemic and kidney cortical tissue) as previously performed in this laboratory $(2,13) .{ }^{125} \mathrm{I}$-labeled bovine serum albumin (5-7 $\mu \mathrm{Ci}$; ICN Biomedicals, Inc., Irvine, CA) in isotonic saline in an equal volume to the labeled erythrocytes was added as a marker of renal albumin kinetics, plasma volume, and systemic transcapillary albumin escape rate $\left(T E R_{a b b}\right)$. Aliquots of this mixture were obtained to determine total radioactivity and the remaining volume was measured and infused into the rat. After $5 \mathrm{~min}$ of the infusion, a $100-200-\mu 1$ sample of whole blood was removed and placed in a preweighed tube for weight determination of the volume and counting on a gamma counter. Blood was also withdrawn at 15,30 , and 60 min after the infusion of the radiolabel. Urine was collected in two 30 -min periods to determine urinary albumin excretion rates. At the end of the 60-min sampling period, a flank incision was quickly performed, exposing the left kidney. The perirenal tissue was separated from the kidney, the renal vasculature was double clamped, and the kidney was excised and immediately immersed in liquid nitrogen to snap-freeze the tissue while the vasculature to the kidney remained clamped. After the kidney was frozen, three sections of renal cortical tissue were ob- tained, weighed, and placed in separate counting vials, as was the remnant kidney, and counted on a gamma counter and compared with whole blood counts obtained at the 60 -min collection time. This procedure was performed in the following groups.

Nondiabetic controls (control, groups $1 a$ and $1 b$ ).

Group 1a (untreated). Nondiabetic rats ( $n=9$, body wt $=283 \pm 16$ $\mathrm{g}$ ) were anesthetized and prepared for radiolabeled isotopes infusion as described above. All above listed parameters were measured, the kidney was excised at the end of the 1-h measurement period, and the animals were euthanized.

Group $1 \mathrm{~b}$ (lysine treated). Nondiabetic rats $(n=4$, body wt $=230 \pm 1 \mathrm{~g}$ ) were used in this group. $30 \mathrm{~min}$ before the infusion of the radiolabeled isotopes, an infusion of lysine ( $10 \%$ solution in isotonic saline, L-2,6-diaminohexanoic acid; Sigma Chemical Co., St. Louis, MO) at a rate of $200 \mathrm{mg} / \mathrm{kg}$ body $\mathrm{wt} \cdot \mathrm{h}$ was initiated and continued throughout the remainder of the study. Lysine administration in this concentration has been shown to prevent or nearly inhibit all tubular protein reabsorption (14). All above listed parameters were measured, the kidney was excised at the end of the 1-h measurement period, and the animals were euthanized.

7-10-d experimental diabetes (IDD 7-10 d, groups $2 a, 2 b$, and $2 c$ ).

Group 2a (untreated). The rats $(n=9$, body wt $=268 \pm 19 \mathrm{~g})$ were anesthetized with a short-acting anesthetic $(65 \mathrm{mg} / \mathrm{kg}$ body wt methohexital sodium, Brevital; Eli Lilly and Company, Indianapolis, IN) and injected via the tail vein with streptozotocin $(65 \mathrm{mg} / \mathrm{kg}$ body wt; Sigma Chemical Co.) to induce experimental IDD $(2,4) 7-10 \mathrm{~d}$ before the study. No insulin treatment was administered to these animals. On the day of the study, the rats were anesthetized and prepared for the study as described above. All above listed parameters were measured, the kidney was excised at the end of the 1-h measurement period, and the animals were euthanized.

Group $2 b$ (lysine treated). Streptozotocin diabetes was induced in rats $(n=9$, body $w t=244 \pm 6 \mathrm{~g})$ in the same fashion as group $2 \mathrm{a}$ and prepared for the study as described above. However, $30 \mathrm{~min}$ before the infusion of the radioisotopes, an infusion of lysine (10\% solution in isotonic saline) was initiated at a rate of $200 \mathrm{mg} / \mathrm{kg}$ body $\mathrm{wt} \cdot \mathrm{h}$ and continued throughout the remainder of the study. All above listed parameters were measured, the kidney was excised at the end of the 1-h measurement period, and the animals were killed.

Group 2c (insulin treated). Streptozotocin diabetes was induced in rats $(n=5$, body $w t=248 \pm 19 \mathrm{~g})$ as described above. For the first $24 \mathrm{~h}$, the rats were untreated followed by daily treatment with 2-8 $\mathrm{U}$ of heat-treated Ultralente insulin (Novo Nordisk Biolabs, Danbury, CT) to maintain blood glucose concentrations at euglycemic levels. Blood glucose concentrations were monitored daily (between 2 and 4 p.m.) and the rats were injected subcutaneously with insulin accordingly for 7-10 d. At the end of the treatment period, the rats were anesthetized and prepared for the measurement period as described above. All above listed parameters were measured, the kidney was excised at the end of the 1-h measurement period, and the animals were euthanized. This group was used to determine if there was any potential streptozotocin toxicity effects on the factors measured in the 7-10-d IDD rats.

50-70-d moderately controlled, experimental diabetes (IDD 50-70 $d$, groups $3 a$ and $3 b$ ).

Group 3a (moderately controlled hyperglycemia). Streptozotocin diabetes was induced in rats $(n=5$, body $w t=272 \pm 8 \mathrm{~g})$ as described for group 2a. On the second day after streptozotocin administration, the rats were injected subcutaneously with heat-treated ultralente insulin $(0.4-1.0 \mathrm{U} / \mathrm{d})$ daily to maintain blood glucose concentrations at $275-325 \mathrm{mg} / \mathrm{dl}$ for $50-70 \mathrm{~d}$. Blood glucose concentrations and body weight were monitored weekly until the time of the study. On the day of the study, the rats were anesthetized and prepared as described above. All above listed parameters were measured, the kidney was excised at the end of the 1-h measurement period, and the animals were euthanized.

Group 3b (lysine-treated moderately controlled hyperglycemia). Streptozotocin diabetes was induced in rats $(n=5$, body $w t=277 \pm 7 \mathrm{~g})$ as described for group $2 \mathrm{a}$ and treated with insulin as in group $3 \mathrm{a}$ for 
50-70 d. On the day of the study, the rats were anesthetized and prepared as described above. $30 \mathrm{~min}$ before the infusion of radioisotopes, lysine ( $10 \%$ solution in isotonic saline) was administered intravenously at a rate of $200 \mathrm{mg} / \mathrm{kg}$ body $\mathrm{wt} \cdot \mathrm{h}$ and continued throughout the remainder of the study. All above listed parameters were measured, the kidney was excised at the end of the 1-h measurement period, and the animals were euthanized.

\section{Measurement of GFR}

Due to the high crossover of ${ }^{125} \mathrm{I}$ and ${ }^{3} \mathrm{H}$ counts in a scintillation counter, $\left[{ }^{3} \mathrm{H}\right]$ inulin clearances were performed in separate groups of rats to measure GFR. On the morning of the study, the rats were anesthetized with Inactin administered intraperitoneally. Catheters were emplaced in the rats as described in the previously protocol. An infusion of $\left[{ }^{3} \mathrm{H}\right]$ inulin in saline $(1.5 \mathrm{ml} / \mathrm{h})$ was initiated $60 \mathrm{~min}$ before the measurement period and continued throughout the remainder of the study. Two kidney GFR was measured in four groups of rats to ascertain the relationship of albumin filtration to GFR. The four groups were: $(a)$ nondiabetic controls as described in group la $(n=6),(b)$ 7-10-d untreated streptozotocin diabetics as described in group $2 \mathrm{a}(n$ $=6$ ), (c) 7-10-d insulin-treated streptozotocin diabetics as described in group 2c $(n=5)$, and $(d) 50-70$-d moderately controlled streptozotocin diabetic rats as described in group $3 \mathrm{a}(n=8)$. At least two measurements of GFR were obtained in each rat. At the end of the measurement period, the rats were euthanized and the kidneys were weighed.

\section{Determination of interstitial protein concentration}

Two groups of rats were used in determining the systemic plasma/ renal interstitium albumin ratio. The two groups were nondiabetic controls as in group $1 \mathrm{a}(n=5)$ and 50-70-d streptozotocin diabetic rats as in group $3 \mathrm{a}(n=8)$. The rats were anesthetized with Inactin and prepared for micropuncture as previously described (15). In brief, an infusion of isotonic $\mathrm{NaCl}-\mathrm{NaHCO}_{3}$ solution was maintained throughout the surgical preparation and measurement period at a rate of $0.6 \%$ body $\mathrm{wt} / \mathrm{h}$. The kidney was placed in a kidney cup, and the cup was sealed with cotton and agar (15). Mineral oil was suffused over the exposed surface of the kidney where the subcapsular fluid was to be collected. An oil-filled glass pipette (6-9 $\mu \mathrm{m})$ was inserted immediately beneath the kidney capsule at a shallow angle usually adjacent to a peritubular capillary. With any evidence of bleeding or puncturing a tubule, a new collection site was located. Usually, three individual collections were performed with a collection time of 20-40 min each. Gentle aspiration was used sufficient to obtain $60-80 \mathrm{nl}$ of subcapsular fluid as previously performed in our laboratory (16). Total protein measurements of these samples were analyzed individually as previously performed (16).

\section{Morphometric determination of renal cortical interstitial} volume and proximal tubule dimensions

Morphometric measurements of renal cortical interstitial volume and proximal tubule dimensions were obtained in three groups of rats similar treatment protocols as group la (nondiabetic controls, $n=5$ ), group 2a (7-10-d IDD, $n=4)$, and Group 3a (50-70-d IDD, $n=9$ ).

Tissue preparation. The kidneys were fixed by a retrograde perfusion performed through the aorta with $1 \%$ glutaraldehyde in a modified Tyrode buffer for $4 \mathrm{~min}$ at a pressure of $140 \mathrm{mmHg}(17,18)$. Only the kidneys that blanched immediately and homogeneously, indicating optimal perfusion, were selected. After fixation of the tissue, the left kidney was removed and weighed, and then stored in the same solution. Randomized $(2 \times 2 \mathrm{~mm})$ blocks of tissue from the midcortex and from the outer stripe of the outer medulla (OSOM) were randomly selected and stained with osmium and embedded in Epon $(17,18)$. Only the cortex and the OSOM comprising $80 \%$ of the kidney was used for the study. This was because of the fact that perfusion fixation of all kidney zones is not possible with the same fixative since the medulla has to be fixed with a solution of higher osmolarity (19). 2- $\mu$ m-thick sections were cut from five blocks in each animal on an Ultratome III (LKB, Stockholm, Sweden) and stained with tuludin blue and PSA.
Light microscopy and quantification. The stained sections were examined with an BII-2 microscope (model BII-2; Olympus Corp., Lake Success, NY) provided with a mirror which projects the sections onto a screen. The screen had a rectangular grid in which the number of tubular profiles within the frame was counted, using the unbiased counting role (18). By application of a point count technique (18), the volume fraction of lumen, brush border, and tubular tissue, normal and glycogen containing, was measured. In the counting procedure, differentiation between proximal tubules and distal tubules were made. The distal tubule included the distal straight tubule, the distal convoluted tubule, and the connecting tubule, but not the cortical collecting duct. PASpositive material (glycogen) in the thick ascending limb was counted. The interstitium was quantified without any subdivision by locale or content of this region.

The total tubular volume was estimated by $V_{\mathrm{v}}$ (tubules/cortex) $\times V_{\mathrm{y}}$ (cortex/kidney) $\times$ kidney weight $(\mathrm{KW})$ and the total brush border and tubular lumen were calculated in the same fashion. The total tubular length per unit volume, $L_{\mathrm{v}}$, is estimated by $2 \times N_{\mathrm{a}}$, where $N_{\mathrm{a}}$ is the number of tubular profiles per unit cortical area on the thin plastic sections. The total length of the tubules is $2 \times N_{\mathrm{a}}$ (tubules/cortex) $\times V_{\mathrm{v}}$ (cortex/kidney) $\times \mathrm{KW}$. The average cross-sectional area perpendicular to the longitudinal direction of the tubular structure is $\bar{A}$ $=\mathrm{V} / \mathrm{L}$, which is estimated by $V_{\mathrm{v}} / L_{\mathrm{v}}$. Assuming a circular cross section, the average diameter of the tubules can be calculated as $\bar{d}=2$ $\times(\bar{A} / \pi)^{1 / 2}$ and the average height, $h$, of the tubular cells in then calculated as $1 / 2 \times\left(d_{\mathrm{e}}-d_{1}\right)$, e and $l$ indicating the external and the luminal diameter, respectively. The interstitial volume, $V_{\mathrm{i}}$, was calculated as $V_{\mathrm{v}}$ (interstitium/total interstitium) $\times($ cortex $/$ kidney $) \times \mathrm{KW}$. These calculations are used as previously published (20).

\section{Analytical methods}

Measurement of renal cortical nonvascular albumin distribution volume. Calculations for extravascular albumin distribution volumes in the renal cortex are based upon the escape or transport of [ $\left.{ }^{125} \mathrm{I}\right]-$ albumin into the tubule and interstitium over $60 \mathrm{~min}$ and the concentration of albumin in the interstitium as previously published (16).

Blood volume (BV) in each renal cortical tissue sample was determined by the following equation:

\section{$\mathrm{BV} /$ tissue sample}

\section{$={ }^{51} \mathrm{Cr} \mathrm{cpm}$ in tissue $/{ }^{51} \mathrm{Cr} \mathrm{cpm} / \mu \mathrm{l}$ of systemic blood,}

where the hematocrit used for a microliter of systemic blood is the uncorrected measured systemic hematocrit. This hematocrit value is an overestimate of systemic hematocrit; true systemic hematocrit was determined to be $96 \%$ of the uncorrected hematocrit. [ ${ }^{125} \mathrm{I}$ ] albumin counts in extravascular space (ES) were determined by the following equation:

$$
\begin{aligned}
& \mathrm{ES}^{125} \mathrm{I} \mathrm{cpm}=\text { total tissue }{ }^{125} \mathrm{I} \mathrm{cpm} \\
& -\left(\text { tissue } \mathrm{BV} \times{ }^{125} \mathrm{I} \mathrm{cpm} / \mu \mathrm{l} \text { of blood }\right)
\end{aligned}
$$

Because $\left[{ }^{125} \mathrm{I}\right]$ albumin should distribute in plasma and renal interstitium in the same ratio as does endogenous albumin, we determine the nonvascular albumin distribution volume $\left(\mathrm{Vd}_{\mathbf{a l b}}{ }^{\prime}\right)$ in the following manner:

$$
\mathrm{Vd}_{\mathrm{alb}}{ }^{\prime}=\left(\mathrm{ES}^{125} \mathrm{I} \mathrm{cpm} /{ }^{125} \mathrm{I} \mathrm{cpm} / \mu \mathrm{l} \text { of plasma }\right)
$$

$\times$ (plasma albumin concentration/interstitial albumin concentration)

Interstitial albumin concentration was determined from the subcapsular protein concentrations, measured by a microadaption ( 21 ) of the method of Lowry et al. ( 10 ) as previously described by this laboratory (15), in rats used in the interstitial protein concentration protocol and the previously determined renal interstitial albumin/(A/G) ratio (22). Plasma albumin concentration was previously determined to be $\sim 50 \%$ of systemic protein concentration (22). To determine a percentage value of renal cortical nonvascular albumin distribution $\left(\mathrm{Vd}_{\mathrm{alb}}\right)$, we used the following relationship: $\mathrm{VD}_{\mathrm{alb}}=\left(\mathrm{Vd}_{\mathrm{alb}}{ }^{\prime} /\right.$ snap-fro- 
zen tissue $w t) \times 100$. Calculations similar to these to determine interstitial volume have been performed previously by our laboratory (14).

Measurement of systemic $T E R_{a l b}$. The systemic TER $R_{\text {alb }}$ was measured as previously described ( 2 ) and as described by Parving and Gyntelberg (23) and Feld-Rasmussen (24) with minor modifications. Total area under the albumin disappearance curve in the first $60 \mathrm{~min}$ was used to measure TER alb. Because there is a high TER $_{\text {alb }}$ in rats compared with humans, equilibration of label into extracellular fluid space occurs at a rapid pace, resulting in a return of the $\left[{ }^{125} \mathrm{I}\right]$ albumin to vascular space from the lymphatics and, therefore, the measured TER $_{\text {alb }}$ could be an underestimate of true values.

${ }^{51} \mathrm{Cr}$-labeled erythrocytes and [ $\left.{ }^{125} \mathrm{I}\right]$ albumin were also used to determine blood volumes.

Measurement of urinary albumin excretion. Urinary albumin excretion $\left(\mathrm{U}_{\mathrm{alb}}\right)$ rates were determined by the following equation:

$\mathrm{U}_{\mathrm{alb}}=\left[\left({ }^{125} \mathrm{I}\right]\right.$ albumin $/ \mu \mathrm{l}$ urine $) \times$ urine flow $] /$

[( $\left.{ }^{125} \mathrm{I}\right]$ albumin $\mathrm{cpm} / \mu \mathrm{l}$ plasma $) /($ plasma albumin $\left./ \mu \mathrm{l})\right]$

This technique was used because $\left[{ }^{125} \mathrm{I}\right]$ albumin was infused into the rats for other measurements, eliminating the need for chemical methods of determining urinary albumin excretion.

Determination of urinary space albumin concentration. The concentration of albumin in urinary space can only be estimated because of the circumstances that the data are derived from different groups of animals and an assumption must be made that lysine treatment as used in the present study does not alter glomerular filtration rate. Urinary space albumin concentration $\left(\mathrm{US}_{\mathrm{alb}}\right.$ ) is derived from the GFR measurement from the rats used in the GFR protocol and the lysine-treated rats in groups $1 \mathrm{~b}, 2 \mathrm{~b}$, and $3 \mathrm{~b}$ in the following equation:

$\mathrm{US}_{\mathrm{alb}}=\mathrm{U}_{\mathrm{alb}} /$ GFR.

Determination of confidence interval (SE) for $\mathrm{US}_{\mathrm{abb}}$ was determined by the variance in specific $U_{\text {alb }}$ and GFR for each treatment group and applied to the above formula (25).

Statistical analysis. Statistical significance between groups of animals was evaluated by analysis of variance or Tukey's analysis. Twoway analysis of variance was used to determine significant differences in TER $_{\text {alb }}$ between groups with correction for unpaired grouping (25). All data are given as means \pm SE.

\section{Results}

Effects of 7-10- and 50-70-d diabetes on systemic parameters. Blood glucose concentration (BG), systemic protein concentration $\left(C_{A}\right)$, hematocrit $(H T)$, and $B V$ for the various conditions and subgroups are depicted in Table I. Lysine treatment did not affect any of the systemic parameters assessed in the three conditions. Insulin treatment sufficient to restore BG to euglycemic values during the 7-10-day treatment period did not affect $\mathrm{Hct}, \mathrm{C}_{\mathrm{A}}$, or $\mathrm{BV}$. TER $\mathrm{T}_{\mathrm{alb}}$ for the various conditions and groups within each condition are depicted in Fig. 1. TER $\mathrm{T}_{\mathrm{alb}}$ was significantly increased in both 7-10- and 50-70-d IDD from $17 \pm 2$ in controls to $36 \pm 6$ and $44 \pm 5 \%$ albumin $/ \mathrm{h}$, respectively (Fig. 1). Lysine treatment did not significantly affect TER $_{\text {alb }}$ within the three groups ( $17 \pm 2$ vs. $21 \pm 2 \%$ albumin $/ \mathrm{h}$ in untreated vs. lysine-treated controls, $36 \pm 6$ vs. $29 \pm 2 \%$ albu$\mathrm{min} / \mathrm{h}$ in $7-10-\mathrm{d}$ IDD, and $44 \pm 5$ vs. $40 \pm 2 \% \mathrm{albumin} / \mathrm{h}$ in 50-70-d IDD, Fig. 1). Insulin treatment in 7-10-d IDD rats (group $2 c$ ) resulted in a value for $\operatorname{TER}_{\mathrm{alb}}(15 \pm 2 \%$ albumin $/ \mathrm{h}$ ) that was not different from control values (Fig. 1). These data indicate that systemic transcapillary escape of albumin is increased in diabetes both in early phases of the disease as previously demonstrated (2) and in chronic conditions.

Effects of 7-10- and 50-70-d diabetes on GFR. GFR in control, 7-10-d IDD (both untreated and insulin treated), and
Table I. Effect of 7-10- and 50-70-d Experimental Diabetes on Blood Glucose Concentration, Hematocrit, Blood Volume, and Systemic Protein Concentration

\begin{tabular}{|c|c|c|c|c|}
\hline & BG & Hct & BV & $\mathrm{C}_{\mathrm{A}}$ \\
\hline & $m g / d l$ & $\%$ & \% body wt & $g / d l$ \\
\hline Control (1a) & $129 \pm 5$ & $45 \pm 1$ & $5.9 \pm 0.1$ & $4.7 \pm 0.1$ \\
\hline \multicolumn{5}{|l|}{ Control } \\
\hline+ lysine (1b) & $113 \pm 8$ & $47 \pm 1$ & $5.6 \pm 0.2$ & $4.4 \pm 0.2$ \\
\hline $7-10-d$ IDD (2a) & $354 \pm 18^{*}$ & $47 \pm 1$ & $5.8 \pm 0.3$ & $5.1 \pm 0.3$ \\
\hline \multicolumn{5}{|l|}{$7-10-d$ IDD } \\
\hline+ lysine $(2 b)$ & $333 \pm 12^{*}$ & $46 \pm 1$ & $5.7 \pm 0.2$ & $4.3 \pm 0.2^{\ddagger}$ \\
\hline \multicolumn{5}{|l|}{$7-10-d$ IDD } \\
\hline+ insulin $(2 c)$ & $94 \pm 22^{\ddagger}$ & $42 \pm 2$ & $5.5 \pm 0.2$ & $4.5 \pm 0.1$ \\
\hline 50-70-d IDD (3a) & $272 \pm 8^{*}$ & $47 \pm 1$ & $5.9 \pm 0.1$ & $4.5 \pm 0.1$ \\
\hline \multicolumn{5}{|l|}{ 50-70-d IDD } \\
\hline+ lysine $(3 b)$ & $277 \pm 7^{*}$ & $47 \pm 1$ & $5.6 \pm 0.2$ & $4.4 \pm 0.2$ \\
\hline
\end{tabular}

${ }^{*} P<0.05$ compared with control values. $\quad{ }^{\ddagger} P<0.05$ compared with respective untreated group.

50-70-d IDD rats are depicted in Fig. 2. GFR in both 7-10and 50-70-d IDD was significantly increased compared with control values $(2.7 \pm 0.1 \mathrm{ml} / \mathrm{min}$ in $7-10-\mathrm{d}$ IDD and $2.6 \pm 0.1$ $\mathrm{ml} / \mathrm{min}$ in 50-70-d IDD compared with $2.2 \pm 0.1 \mathrm{ml} / \mathrm{min}$ in control, Fig. 2). GFR between control and insulin-treated $7-10-d$ IDD was not different $(2.2 \pm 0.1$ vs. $2.1 \pm 0.1 \mathrm{ml} / \mathrm{min}$, respectively, Fig. 2). Increased GFR was observed at both the 7-10- and 50-70-d time points in experimental diabetes in the present study. If GFR is normalized to snap-frozen kidney weight ( $\mathrm{KW}$ ) (assuming both left and right kidneys are equivalent in weight, Table II) in each of the three treatment protocols, then GFR/gm KW would result in values of $0.77 \pm 0.06$ $\mathrm{ml} / \mathrm{min} \cdot \mathrm{gm} \mathrm{KW}$ in control, $0.74 \pm 0.03 \mathrm{ml} / \mathrm{min} \cdot \mathrm{gm} \mathrm{KW}$ in $7-10-\mathrm{d}$ IDD, and $0.62 \pm 0.06 \mathrm{ml} / \mathrm{min} \cdot \mathrm{gm} \mathrm{KW}$ in $50-70-\mathrm{d}$ IDD. These values for GFR are not significantly different from one another.

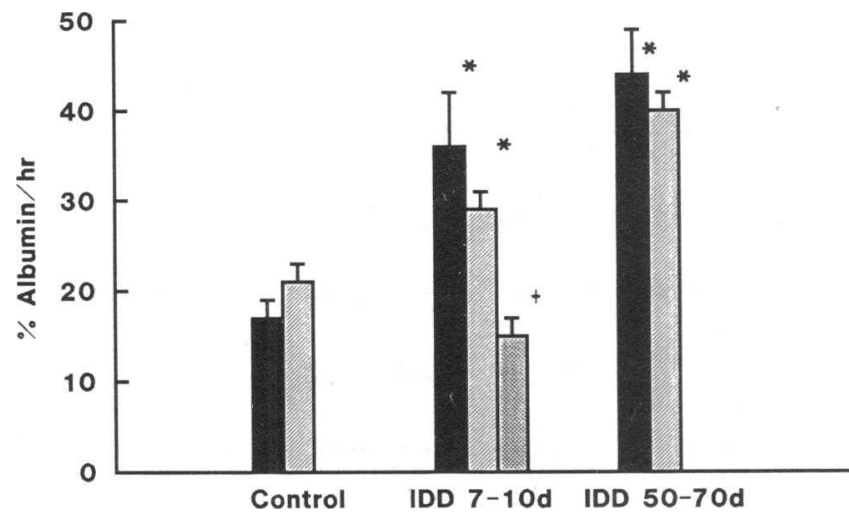

Figure 1. Effect of 7-10- and 50-70-d diabetes on TER $\mathrm{Aab}_{\mathrm{ab}}$ TER $_{\mathrm{alb}}$ increased significantly in both 7-10- and 50-70-d diabetic rats (solid bars, groups 2a and 3a vs. 1a). Lysine treatment had no effect on $\mathrm{TER}_{\mathrm{alb}}$ among the three groups (hatched bars, groups $1 \mathrm{~b}, 2 \mathrm{~b}, 3 \mathrm{~b}$ ). Insulin treatment in 7-10-d IDD, sufficient to restore blood glucose concentrations to euglycemic values, also prevented the increase in $\mathrm{TER}_{\text {alb }}$ (crosshatched bar, group $2 \mathrm{c}$ ). ${ }^{*} P<0.05$ compared with control. 


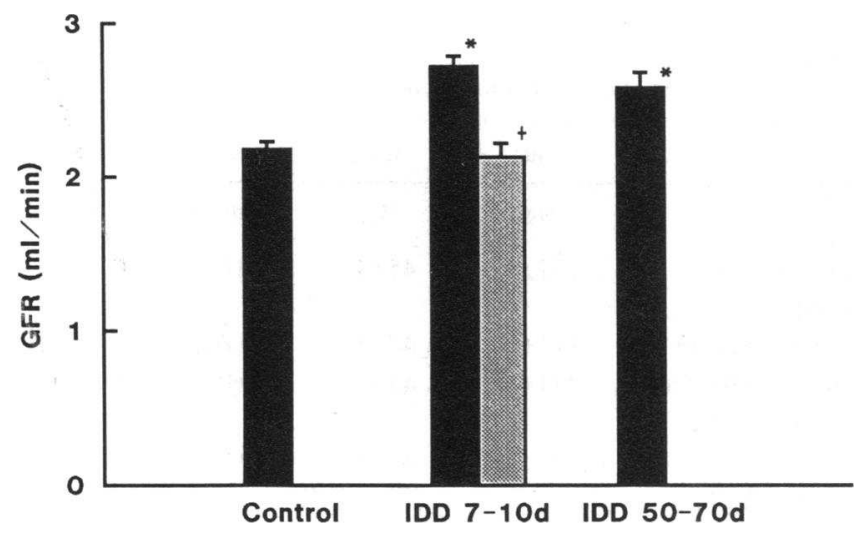

Figure 2. Effect of 7-10- and 50-70-d diabetes on GFR. GFR increased in both 7-10-d and 50-70-d IDD compared with control, indicating hyperfiltration in both preproteinuric and proteinuric phases of experimental diabetes (solid bars). Insulin treatment prevented the increase in GFR in 7-10-d IDD (crosshatched bar). ${ }^{*} P<0.05$ compared with control.

Systemic/interstitial albumin concentration ratios. In the separate group of nondiabetic, control rats, systemic protein concentration was $5.2 \pm 0.3$ and $1.4 \pm 0.3 \mathrm{~g} / \mathrm{dl}$ in subcapsular space. Given an AG ratio of $1: 1$ in the systemic plasma and an $A G$ ratio of $2: 1$ in the interstitium (20), the ratio of systemic to interstitial albumin is $2.6: 1$ in these control rats. This systemic to interstitial albumin ratio is not different from a previously determined value of $2.5: 1$ in control rats (16). In the 50-70-d IDD rats, systemic protein concentration was $4.7 \pm 0.2 \mathrm{~g} / \mathrm{dl}$ and subcapsular protein concentration was $1.1 \pm 0.2 \mathrm{~g} / \mathrm{dl}$, resulting in systemic/interstitial albumin ratio of $2.8: 1$, a value not different from control rats. Therefore, these values were averaged (2.7) and the mean systemic/interstitial albumin ratio was used to determine $\mathrm{Vd}_{\mathrm{alb}}$ for all three conditions. Errors in assessment of interstitial albumin would affect absolute values of
$\mathrm{Vd}_{\mathrm{abb}}$ but not alter the difference in renal cortex albumin accumulation between lysine-treated and nonlysine-treated rats. If significant errors occurred in these measurements, then $\mathbf{V d}_{\mathrm{alb}}$ in lysine-treated rats would be markedly different from morphometric assessment of interstitial space.

Effect of 7-10- and 50-70-d diabetes on $V_{\text {alb }}$ volume in the renal cortex and comparison to interstitial space. $\mathrm{Vd}_{\mathrm{alb}}$ and morphometric determination of interstitial space are depicted in the renal cortex for control, 7-10-d, and 50-70-d IDD conditions (Fig. 3). Any significant increase in $\mathrm{Vd}_{\mathrm{alb}}$ compared with morphological measurements of interstitial space is indicative of intracellular accumulation of albumin in the tubule. $\mathrm{Vd}_{\mathrm{alb}}$ in control rats (group 1a) was $23 \pm 1 \%$ of renal cortical volume (Fig. 3, first bar, Control) and acute lysine treatment (group 1b) did not alter this value ( $23 \pm 2 \%$, NS, Fig. 3, second bar, Control). Neither of these values were different from morphometric determination of interstitial volume $(21 \pm 2 \%$, Fig. 3 , third bar, Control). In the 7-10-d IDD rats (group 2a), $\mathrm{Vd}_{\mathrm{alb}}$ (Fig. 3, first bar, IDD 7-10d) was significantly increased compared with control rats (group 1a) ( $37 \pm 4$ vs. $23 \pm 1 \%$ in control, $P<0.05)$. Lysine treatment, sufficient to block tubular reabsorption of albumin, in 7-10d IDD (group 2b, Fig. 3, second bar, IDD 7-10d) resulted in a value for $\mathrm{Vd}_{\text {alb }}$ of $20 \pm 1 \%$ that was considerably less than that of the nonlysine-treated rats in this group (group $2 \mathrm{a}, 37 \pm 4 \%$, Fig. 3), indicating significant tubular reabsorption of protein in 7-10-d IDD rats that was prevented by lysine. In addition, the value for $\mathrm{Vd}_{\mathrm{alb}}$ in the lysine-treated 7-10-d IDD group (2b) was not different compared with nondiabetic control values (group $2 b$ vs. 1b, Fig. 3 ). In insulin-treated, euglycemic 7-10-d IDD rats (group 2c) $\mathrm{Vd}_{\mathrm{alb}}$ was $25 \pm 2 \%$, a value not different compared with nondiabetic values (Fig. 3, third bar, IDD, 7-10d) indicating that the increase in $\mathrm{Vd}_{\mathrm{alb}}$ observed in untreated 7-10-d IDD is not the result of streptozotocin toxicity. Morphometric assessment of renal cortical interstitial space was $19 \pm 1 \%$ (Fig. 3, fourth bar, IDD 7-10-d) in 7-10-d IDD rats, a value significantly less than the untreated 7-10-d IDD value of $\mathrm{Vd}_{\text {alb }}$ (group 2a) but not

Table II. Effect of 7-10-d and 50-70-d Experimental Diabetes on Body Weights, Snap Frozen Kidney Weights, Proximal Tubule Lengths, Diameters, and Brush-Border Heights

\begin{tabular}{|c|c|c|c|c|c|c|c|}
\hline & Body wt & Kidney wt & $\mathrm{KW} / \mathrm{BW}$ & $\begin{array}{l}\text { Proximal tubule } \\
\text { diameter }\end{array}$ & $\begin{array}{l}\text { Proximal tubule } \\
\text { length }\end{array}$ & $\begin{array}{c}\text { Proximal tubule } \\
\text { area }\end{array}$ & $\begin{array}{l}\text { Proximal tubule } \\
\text { brush-border height }\end{array}$ \\
\hline \multicolumn{4}{|c|}{$g$} & $\mu m$ & $m$ & $\mathrm{~cm}^{2}$ & $\mu m$ \\
\hline Control (1a) & $283 \pm 16$ & $1.42 \pm 0.12$ & $0.0050 \pm 0.0003$ & $28 \pm 1$ & $246 \pm 14$ & $216 \pm 10$ & $5.0 \pm 0.3$ \\
\hline \multicolumn{8}{|l|}{ Control } \\
\hline + lysine (lb) & $230 \pm 1$ & $1.32 \pm 0.18$ & $0.0057 \pm 0.0004$ & - & - & - & - \\
\hline \multicolumn{8}{|l|}{ 7-10-d IDD } \\
\hline \multicolumn{8}{|l|}{$7-10-d$ IDD } \\
\hline+ lysine $(2 b)$ & $244 \pm 6$ & $1.86 \pm 0.05^{*}$ & $0.0076 \pm 0.0004^{*}$ & - & 一 & - & - \\
\hline \multicolumn{8}{|l|}{$7-10-\mathrm{d}$ IDD } \\
\hline+ insulin $(2 c)$ & $248 \pm 19$ & $1.24 \pm 0.08^{\ddagger}$ & $0.0049 \pm 0.0005^{\ddagger}$ & 一 & - & - & - \\
\hline \multicolumn{8}{|l|}{ 50-70-d IDD } \\
\hline$(3 a)$ & $272 \pm 8$ & $2.11 \pm 0.12^{*}$ & $0.0078 \pm 0.0006^{*}$ & $38 \pm 2^{*}$ & $290 \pm 15^{*}$ & $346 \pm 15^{*}$ & $3.8 \pm 0.2^{*}$ \\
\hline \multicolumn{8}{|l|}{ 50-70-d IDD } \\
\hline+ lysine $(3 b)$ & $277 \pm 7$ & $2.25 \pm 0.10^{*}$ & $0.0081 \pm 0.0006^{*}$ & - & - & - & - \\
\hline
\end{tabular}

${ }^{*} P<0.05$ compared with control. ${ }^{\ddagger} P<0.05$ compared with respective untreated IDD group. Proximal tubule dimensions were obtained in separate groups of rats as described in Methods. 


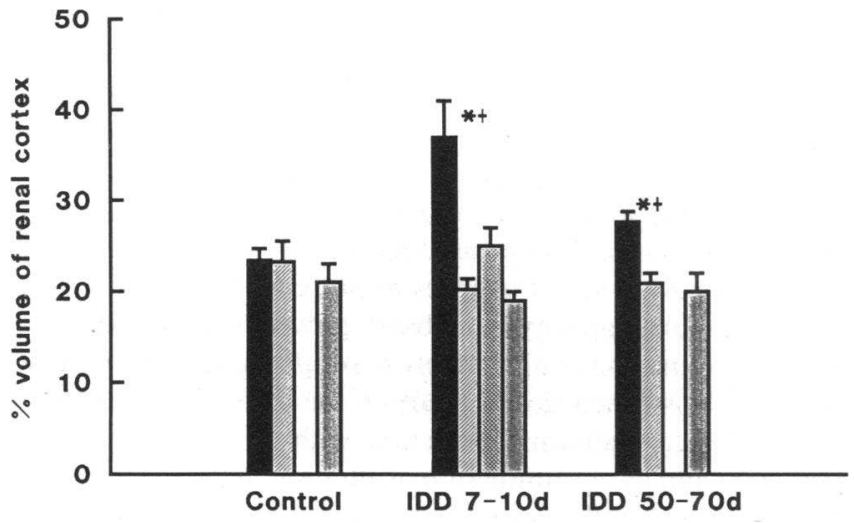

Figure 3. Effect of 7-10- and 50-70-d diabetes on $\mathrm{Vd}_{\mathrm{alb}}$ in the renal cortex with comparisons to morphometric assessment of interstitial space. $\mathrm{Vd}_{\mathrm{alb}}$ increased in both 7-10- and 50-70-d IDD compared with control (solid bars, groups $2 \mathrm{a}$ and $3 \mathrm{a}$ vs. $1 \mathrm{a}$ ). Increases in $\mathrm{Vd}_{\mathrm{alb}}$ $>$ interstitial space indicate intracellular accumulation of albumin in the tubules. Lysine treatment, to prevent tubular albumin reabsorption, had no effect on $\mathrm{Vd}_{\text {alb }}$ in control but significantly decreased $\mathrm{Vd}_{\text {alb }}$ in both 7-10- and 50-70-d IDD to values not different from control (hatched bars, groups $2 \mathrm{~b}$ and $3 \mathrm{~b}$ vs. $1 \mathrm{~b}$ ). $\mathrm{Vd}_{\mathrm{alb}}$ in insulin treated 7-10-d IDD rats was not different from control (crosshatched bar, group 2c). The morphometric measurements of interstitial space are depicted by the fine-hatched bars and the values for control and lysine-treated rats are not different from these measurements. ${ }^{*} P<0.05$ compared with interstitial space, ${ }^{\dagger} P<0.05$ compared with lysinetreated rats.

different compared with the lysine-treated 7-10-d IDD rats

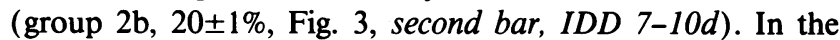
50-70-d IDD rats (group $3 \mathrm{a}$ ), $\mathrm{Vd}_{\mathrm{alb}}$ was $28 \pm 1 \%$ (Fig. 3 , first bar, IDD 50-70d), which was significantly greater than control (group la, 23 $\pm 1 \%$, Fig. 3, first bar, Control). Lysine treatment decreased $\mathrm{Vd}_{\mathrm{alb}}$ in $50-70-\mathrm{d}$ IDD to $21 \pm 1 \%$ (group 3b, Fig. 3, second bar, IDD 50-70d) to a value not different from morphometric measurements of interstitial space $(20 \pm 2 \%$, Fig. 3 , third bar, IDD 50-70d). In addition, $\mathrm{Vd}_{\mathrm{alb}}$ in 50-70-d IDD was significantly less than $\mathrm{Vd}_{\mathrm{alb}}$ in $7-10$-d IDD $(28 \pm 1$ vs. $37 \pm 4 \%$, groups 2 a vs. $3 \mathrm{a}$, respectively, $P<0.05$, Fig. 3 ), indicating that tubular reabsorption of protein was less in 50-70-d IDD than in $7-10-d$ rats.

Lysine treatment in all three groups returned $\mathrm{Vd}_{\mathrm{alb}}$ to values not different than morphometric measurements of interstitial space, indicating that in both 7-10- and 50-70-d IDD, there is significant accumulation of albumin in spaces other than the vasculature or interstitium in the renal cortex. It is most likely that, because lysine treatment has been previously demonstrated to block tubular reabsorption of albumin, this additional renal cortical accumulation of albumin was within the tubular cells.

Effect of 7-10- and 50-70-d diabetes on $U_{\text {alb }} . \mathrm{U}_{\mathrm{alb}}$ in nondiabetic controls, 7-10, and 50-70-d IDD in both nonlysine and lysine-treated rats are depicted in Fig. 4. $U_{\text {alb }}$ was $20 \pm 3 \mu \mathrm{g} / \mathrm{min}$ in untreated control (group 1a) and $30 \pm 6 \mu \mathrm{g} / \mathrm{min}$ in lysinetreated control (group 1b, NS; Fig. 4, first vs. second bar, Control). In nonlysine-treated 7-10-d IDD (group 2a), $\mathrm{U}_{\text {alb }}$ was $19 \pm 3 \mu \mathrm{g} / \mathrm{min}$, a value not different compared with nondiabetic control (group la, Fig. 4). Lysine treatment significantly increased $U_{\text {alb }}$ in 7-10-d IDD compared with non-lysine treated $7-10$-d IDD ( $67 \pm 10$ vs. $19 \pm 3 \mu \mathrm{g} / \mathrm{min}$, group $2 \mathrm{~b}$ vs. $2 \mathrm{a}$, respec-

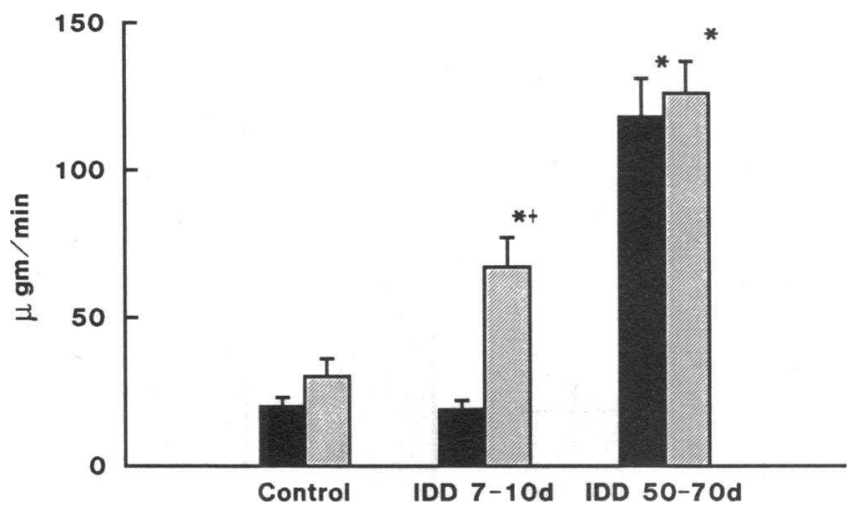

Figure 4. Effect of 7-10- and 50-70-d diabetes on $\mathrm{U}_{\text {alb }}$. There was no change in $\mathrm{U}_{\mathrm{alb}}$ in 7-10-d IDD compared with control (groups 1a vs. $2 a$, solid bars). However, $\mathrm{U}_{\text {alb }}$ increased in 50-70-d IDD (group 3a, solid bar). In lysine-treated rats, to prevent tubular reabsorption of albumin, $U_{\text {alb }}$ was significantly increased in both 7-10- and 50-70-d IDD ( hatched bars, groups $2 \mathrm{~b}$ and $3 \mathrm{~b}$ ), indicating increased glomerular filtration of albumin in both preproteinuric and proteinuric rats. ${ }^{*} P<0.05$ compared with respective control; ${ }^{\dagger} P<0.05$ compared with nonlysine-treated rats.

tively, $P<0.05$, Fig. 4 ), indicating that lysine treatment significantly inhibited reabsorption of albumin. In addition, comparing lysine-treated controls to lysine-treated 7-10-d IDD revealed a significant increase in $U_{\text {alb }}$ in 7-10-d IDD ( $30 \pm 6$ vs. $67 \pm 10 \mu \mathrm{g} / \mathrm{min}$, groups $1 \mathrm{~b}$ vs. $2 \mathrm{~b}$ respectively, $P<0.05$, Fig. 4 ), which is most likely the result of increased glomerular filtration of albumin. In 50-70-d IDD, $\mathrm{U}_{\mathrm{alb}}$ was significantly increased compared with control ( $118 \pm 13$ vs. $20 \pm 3 \mu \mathrm{g} / \mathrm{min}$, groups $3 \mathrm{a}$ vs. 1a, respectively, $P<0.05$, Fig. 4 ), a value which would be considered abnormal protein excretion. Lysine treatment did not significantly alter $\mathrm{U}_{\mathrm{alb}}$ compared with the nonlysine-treated rats in $50-70-\mathrm{d}$ IDD ( $126 \pm 11$ vs. $118 \pm 13 \mu \mathrm{g} / \mathrm{min}$, groups $3 \mathrm{~b}$ vs. 3a, respectively, NS, Fig. 4 ), indicating a reduction in the reabsorptive capacity of the renal tubules in relation to the filtered load of albumin. In addition, in lysine-treated rats, the $\mathrm{U}_{\mathrm{alb}}$ in 50-70-d IDD was significantly greater than observed in $7-10-\mathrm{d}$ IDD $(126 \pm 11$ vs. $67 \pm 10 \mu \mathrm{g} / \mathrm{min}$, groups $3 \mathrm{~b}$ vs. $2 \mathrm{~b}$, respectively, $P<0.05$, Fig. 4 ), suggesting a further increase in albumin passage across the glomerulus. Both the differences in $\mathrm{U}_{\text {alb }}$ between lysine-treated and untreated rats in 7-10-d IDD and the lack of such large difference in 50-70-d IDD confirm the observation of reduction in $\mathrm{Vd}_{\mathrm{alb}}$ in 50-70-d IDD compared with 7-10-d IDD rats. These data suggest that tubular albumin reabsorptive capacity is diminished in 50-70-d IDD.

Effect of 7-10- and 50-70-d diabetes on urinary space albumin concentrations. An approximation of urinary space albumin concentration was obtained by using data from different groups of rats ( see Methods). These calculations yield values of $1.4 \pm 0.3 \mathrm{mg} \%$ in control, $2.5 \pm 0.4 \mathrm{mg} \%$ in $7-10-\mathrm{d}$ IDD, and $4.9 \pm 0.6 \mathrm{mg} \%$ in 50-70-d IDD (Fig. 5). The control values for urinary space albumin concentration are slightly low but within the range that has been observed (1-3 mg\%) (26-28).

Effect of 7-10- and 50-70-d diabetes on kidney size and proximal tubule dimensions. Body weight, snap-frozen left $\mathrm{KW}$, and the $\mathrm{KW} /$ body weight $(\mathrm{BW})$ ratio $(\mathrm{KW} / \mathrm{BW})$ are depicted in Table II. Left KWs were obtained from the combined weights of the sections of the snap-frozen kidneys and therefore will be greater than wet tissue weights previously re- 


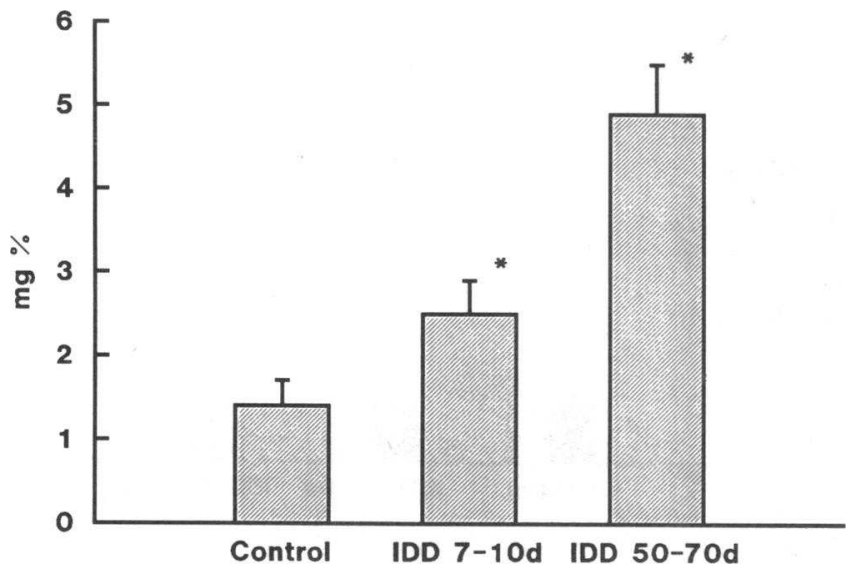

Figure 5. Effect of 7-10- and 50-70-d diabetes on US $_{\text {alb. There were }}$ significant increases in US $_{\text {alb }}$ at both 7-10- and 50-70-d IDD, indicating that increases in GFR were a secondary contributor to the increase in glomerular filtration of albumin in early phases of IDD. ${ }^{*} P$ $<0.05$ compared with control.

ported from this laboratory $(29,30)$ because of the retention of all fluids within the kidney. $\mathrm{KWs}$ and $\mathrm{KW} / \mathrm{BW}$ values were significantly increased in groups where the rats were hyperglycemic (groups 2a, 2b, 3a, 3b, Tables I and II), indicating renal hypertrophy and/or hyperplasia.

Proximal tubule luminal diameter increased only in the 50-70-d IDD rats and not in 7-10-d IDD. In contrast, the length of the proximal tubule increased in 7-10-d IDD rats compared with control ( Table II, $P<0.05$ ) and this increase in length was also observed in the 50-70-d IDD group ( Table II). This resulted in a progressive increase in proximal tubule internal surface area with duration of diabetes ( Table II ). However, proximal tubule brush-border height was unchanged in 7-10-d IDD and decreased in the 50-70-d IDD group (Table II, $P$ $<0.05$ ). The decrease in brush-border height correlates with the decrease in tubular reabsorptive capacity for albumin.

\section{Discussion}

The observation of increased quantities of albumin in the urine that are not sufficient to be detected by standard protein dipstick methods (26-250 mg/24 h) has been designated microalbuminuria and has been increasingly used as a diagnostic indicator for the presence of incipient diabetic nephropathy in humans $(31,32)$. However, this study indicates that increased glomerular filtration of albumin in rats may occur before the detection of microalbuminuria. There are significant renal alterations that occur shortly after the onset of IDD such as renal hypertrophy and glomerular hyperfiltration $(33,34)$ and, in the experimental model, alterations in glomerular basement membrane concentrations of collagen and fibronectin (35), events observed before the onset of microalbuminuria. Previous studies have demonstrated alterations in peripheral vascular macromolecular permeability very early after the onset of IDD (1) and in the streptozotocin model of experimental IDD (2) before any detection of increased protein excretion. It seems quite reasonable to predict that increased glomerular macromolecular permeability may also occur, despite the differing nature of the vascular beds' filtration barrier, before the detection of proteinuria. This event is potentially masked by the substantial protein reabsorptive capacity of the renal tubules.

Impairment of the tubule to reabsorb albumin in early diabetic proteinuria has been previously postulated by Abrass (9), but this defect has not been directly demonstrated. Examination of protein kinetics in the kidney has provided data that demonstrate not only increased glomerular filtration of albumin before detection of changes in protein excretion but also that the tubular capacity to reabsorb protein is decreased with increasing duration of moderately hyperglycemic experimental diabetes. This conclusion is made on the basis of examination of both urinary albumin excretion with and without lysine treatment and the accumulation of albumin in the renal cortex. Morphological findings indicate that the decrease in tubular reabsorptive capacity of albumin correlates best with the decrease in brush-border height and not with increases in luminal surface area or length of the proximal tubule. Because albumin is reabsorbed in the proximal tubule by endocytotic processes that require availability of apical membrane to form lysosomes, the decrease in brush-border height may be indicative of decreased endocytic capacity.

Increased TER $R_{\text {alb }}$ have been previously documented by our laboratory at the onset of experimental diabetes (2) and in rats with diabetes of 6-8 wk duration (36). However, this is the first study in which $\mathrm{TER}_{\text {alb }}$ of the systemic vasculature has been measured in the same animals as glomerular capillary filtration of albumin. It is interesting to note that TER alb $_{\text {was not differ- }}$ ent between 7-10- and 50-70-d diabetic rats, whereas the glomerular filtration of albumin (determined by the $U_{\text {alb }}$ in the lysine-treated rats) increased by approximately a factor of two during the same time period. This would indicate that the mechanisms that affect permeability to macromolecules do not impact glomerular and peripheral capillaries at the same rate or that differences in architecture in the two filtering beds result in differing rates of progression of increased macromolecular permeability. However, it remains possible that true TER $_{\mathrm{alb}}$ has also doubled from 7-10- to 50-70-d from the onset of experimental diabetes, but the 50-70-d value for TER alb $_{\text {was not accu- }}$ rate because of recirculation of albumin through the lymphatics, underestimating the true $T E R_{\text {alb }}$.

In the present study the albumin excretion rates of the control and 7-10-d IDD rats without lysine treatment appear to be high if extrapolated to $24-\mathrm{h}$ excretion rates $(28-29 \mathrm{mg} / \mathrm{d})$. Several factors could account for these high values. (a) Protein excretion rates of rats under anesthesia appear to be much greater than values derived from metabolic cage studies (unpublished observations). (b) Studies were performed in the morning, which is after the rats' feeding period, which can also increase albumin excretion rates (37); and (c) small amounts of unlabeled ${ }^{125}$ I could be excreted, either from infusion of unlabeled ${ }^{125} \mathrm{I}$ or hydrolysis of the albumin by the proximal tubule and the fragment containing the radioisotope excreted, resulting in lower measured fractional albumin reabsorption rates. This latter possibility would impact the nonlysine-treated rats and reduce the observed fraction of tubule albumin reabsorption but not effect the assessment of US $_{\mathrm{alb}}$. However, the accumulation of [ ${ }^{125} \mathrm{I}$ ] albumin within the renal tubular cells confirms the evidence of the change in albumin excretion between lysine and nonlysine-treated rats. Therefore, there is the potential that the albumin excretion rate is not comparable to metabolic cage studies but remains a reasonable qualitative assessment of protein kinetics in the kidney. 
On the basis of the data derived in the present study, an approximation of urinary space albumin concentration $\left(\mathrm{US}_{\mathrm{alb}}\right)$ is provided in Fig. 5. The control values for $\mathrm{US}_{\mathrm{alb}}$ are within the range that has been previously measured (1-3 $\mathrm{mg} \%)(26-28)$. This value significantly increases by $7-10 \mathrm{~d}$ by $\sim 80 \%$ after the onset of diabetes but the actual albumin clearance doubles because of a $25 \%$ increase in GFR. However, there was no difference in the urinary albumin excretion rates between control and 7-10-d IDD as a result of the intrinsic tubular reabsorption capacity. By 50-70-d IDD, urinary space albumin concentration was increased threefold and contributed to significant proteinuria at this phase of experimental diabetes. The major contributor to increased glomerular filtration of albumin is not hyperfiltration but an increase in macromolecular permeability at the glomerular filtration barrier.

Two separate methods, $\mathrm{Vd}_{\mathrm{alb}}$ and untreated and lysinetreated values for $U_{a l b}$, were used to determine the alterations in renal cortical albumin kinetics due to diabetes. Therefore the data provided is at least consistent using both techniques. The data from the present study is internally consistent and can be cross-checked quantitatively in certain respects. In the 7-10$d$ IDD group, there was a significant difference in $U_{\text {alb }}$ between the untreated and the lysine-treated groups. This difference in albumin excretion of $48 \mu \mathrm{g} / \mathrm{min}$ during a study that required $60 \mathrm{~min}$ results in a net difference in albumin excretion between groups of $\sim 3 \mathrm{mg}$. The difference in $\mathrm{Vd}_{\text {alb }}$ between untreated and lysine-treated 7-10-d IDD groups is significant and indicates considerable nonvascular protein accumulation within kidney exclusive of the interstitium. Calculations were then performed to determine the mass of albumin that would have accumulated within the kidney. This value represents an increase of $3 \mathrm{mg}$ of albumin retained in the untreated kidney, which is consistent with the additional $3 \mathrm{mg}$ of albumin excreted in the lysine-treated rats. Given the assumptions inherent to these calculations, the data indicate that the transit time of albumin from brush-border to basolateral membrane is $>60$ $\min$. This value for albumin transit time within the tubular cell is consistent with other studies published in the literature (38).

Early after the onset of untreated or poorly controlled streptozotocin diabetes in the rat there is no evidence of increased albumin excretion (39), which parallels the findings in IDD in humans $(5,40)$. The present study also supports these observations, which demonstrate no increase in albumin excretion at 7-10-d diabetes. However, within 7-10 d after onset of diabetes in this study, there are both increased GFR and renal hypertrophy/hyperplasia. There is evidence that glycation of the glomerulus can occur quite rapidly after exposure to a hyperglycemic environment ( 7) and can potentially alter the permeability of the glomerular filtration barrier. In addition, there are indications of alterations in the composition of the glomerular basement membrane and mesangial extracellular matrix early in the evolution of diabetes (41). All of these changes could contribute to the early increase in glomerular filtration of albumin. A popular explanation for increased filtration of albumin in diabetes is glomerular capillary hypertension $(33,34)$. However, in this model of streptozotocin diabetes, both at 7-10 and 50-70 days duration, studies from this laboratory did not demonstrate an increase in glomerular capillary hydrostatic pressure $(29,42)$. Factors other than glomerular capillary hypertension appear to increase the filtration of albumin in early stages of streptozotocin diabetes.

In summary, these findings present new evidence for in- creased glomerular filtration of albumin before detection of microalbuminuria and correlate on a time line basis with development of increased GFR, glycosylation of the glomerular basement membrane $(4,7)$, and alterations in the composition of the glomerular basement membrane and extracellular matrix material $(9,41)$ but does not correlate to onset of glomerular capillary hypertension. In normal humans acutely treated with lysine, albumin excretion has been shown to be $\sim 300 \mu \mathrm{g} / \mathrm{min}$ $(14,43)$, such that a glomerular defect is not required to account for the presence of microalbuminuria and could result from a reduction in tubular protein reabsorption. The present study demonstrates a decrease in the proximal tubule brushborder height with the reduction in tubular reabsorptive capacity. Studies by Scandling and Myers (32) have demonstrated increased macromolecular sieving in diabetics with microalbuminuria. The present study indicates that microalbuminuria is the result of two factors, a modest, early increase in the glomerular passage of albumin and an eventual decrease in the protein reabsorptive capacity of the tubules in early stages of diabetes. In the 50-70-d diabetic rats, the decrease in tubular reabsorption of protein is significant and contributes to the observed proteinuria. These studies indicate that pathophysiological alterations at the glomerular filtration barrier occur early, resulting in increased glomerular filtration of albumin, and decreased tubular reabsorption of protein contributes to development of microalbuminuria and proteinuria in diabetes.

\section{Acknowledgments}

We thank Dr. T. Meyer, Stanford University, for his helpful suggestions and S. Provost and M. Mendonca for their excellent technical assistance.

This work was supported by a grant, DK39900, from the National Institutes of Health and the Danish Research Foundation.

\section{References}

1. Parving, H.-H., I. Noer, T. Deckert, P.-E. Evrin, S. L. Nielsen, J. Lyngose, C. E. Mogensen, M. Rorth, P. A. Svendsen, J. Trap-Jensen et al. 1976. The effect of metabolic regulation on microvascular permeability to small and large molecules in short-term juvenile diabetics. Diabetologia. 12:161-166.

2. Tucker, B. J. 1990. Early onset of increased transcapillary albumin escape in the awake diabetic rat. Diabetes. 39:919-923.

3. Vittinghus, E., and C. E. Mogensen. 1981. Graded exercise and protein excretion in diabetic man and the effect of insulin treatment. Kidney Int. 21:725729.

4. Tucker, B. J., R. C. Collins, M. G. Ziegler, and R. C. Blantz. 1991. Disassociation between glomerular hyperfiltration and extracellular volume in diabetic rats. Kidney Int. 39:1176-1183.

5. Viberti, G. C., and H. Keen. 1984. The pattern of proteinuria in diabetes mellitus: relevance to pathogenesis and prevention of diabetic nephropathy. Diabetes. 33:686-692.

6. Meyer, T. W. 1990. Mechanisms of proteinuria in diabetic renal disease. Semin. Nephrol. 10:194-202.

7. Tilton, R. G., L. D. Baier, J. E. Harlow, S. R. Smith, E. Ostrow, and J. R. Williamson. 1992. Diabetes-induced glomerular dysfunction: links to a more reduced cytosolic ratio of NAHD/NAD ${ }^{+}$. Kidney Int. 41:778-788.

8. Daniels, B. S., and E. B. Hauser. 1992. Glycation of albumin, not glomerular basement membrane, alters permeability in an in vitro model. Diabetes. 41:1412-1421.

9. Abrass, C. K. 1984. Diabetic proteinuria: glomerular or tubular in origin? Anal. Nephrol. 4:337-346.

10. Lowry, O. H., N. J. Rosebrough, A. L. Farr, and R. J. Randall. 1951. Protein measurement with the Folin phenol reagent. J. Biol. Chem. 193:265275.

11. Sterling, K. 1960. Radioactive chromium technic for circulating red cell volume. Methods Med. Res. 8:69-76. 
12. Sterling, K., and S. J. Gray. 1950. The tagging of red blood cells and plasma protein with radioactive chromium. J. Clin. Invest. 29:1604-1609.

13. Provost, S. B., and B. J. Tucker. 1992. Effect of 14 day head-down tilt on renal function and vascular and extracellular volumes in the conscious rat. Physiologist. 35:S105-S106.

14. Solling, K., and C. E. Mogensen. 1977. Studies on the mechanism of renal tubular protein reabsorption. Proc. Eur. Dial. Transplant Assoc. 14:543-549.

15. Blantz, R. C., and B. J. Tucker. 1978. Measurements of glomerular dynamics. In Methods of Pharmacology, Renal Pharmacology. M. Martinez-Maldonado, editor. Vol. 4b. Plenum Publishing Corp., New York. 141-163.

16. Tucker, B. J., and R. C. Blantz. 1984. Effect of furosemide administration on glomerular and tubular dynamics in the rat. Kidney Int. 26:112-121.

17. Rasch, R., and Osterby, R. 1989. No influence of an aldose reductase inhibitor on glycogen deposition in tubules from streptozotocin diabetic rats. $J$. Diabetic Complications. 3:198-201

18. Gunderson, H. J. 1977. Notes on the estimation of numerical density of arbitrary profiles: the edge effect. J. Microsc. (Oxf.). 111:219-223.

19. Maunsbach, A. B. 1966 . The influence of different fixatives and fixation methods on the ultrastructure of rat kidney proximal tubule cells, II. Effects of varying osmolality, ionic strength, buffer system and fixative concentration of glutaraldehyde solutions. J. Ultrastruct. Res. 15:283-309.

20. Rasch, R. 1984. Tubular lesions in streptozotocin diabetic rats. Diabetolo gia. 27:32-37.

21. Brenner, B. M., K. H. Falchuk, R. D. Keimowitz, and R. W. Berliner. 1969. The relationship between peritubular capillary protein concentration and fluid reabsorption by the renal proximal tubule. J. Clin. Invest. 48:1519-1531.

22. Hargens, A. R., B. J. Tucker, and R. C. Blantz. 1977. Renal lymph protein in the rat. Am. J. Physiol. 233:F269-F273.

23. Parving, H. H., and F. Gyntelberg. 1973. Transcapillary escape rate of albumin and plasma volume in essential hypertension. Circ. Res. 32:643-651.

24. Feld-Rasmussen, B. 1986. Increased transcapillary escape rate of albumin in type 1 (insulin dependent) diabetic patients with microalbuminuria. Diabetologia. 29:282-286.

25. Zar, J. H. 1984. Biostatistical Analysis. Prentice-Hall, Englewood Cliffs, NJ.

26. Oken, D. E., S. C. Cotes, and C. W. Mende. 1972. Micropuncture studies of tubular transport of albumin in rats with aminonucleoside nephrosis. Kidney Int. 1:3-11.

27. Bertolatus, J. A., and L. G. Hunsicker. 1985. Glomerular sieving of anionic and neutral bovine albumins in proteinuric rats. Kidney Int. 28:467-476.

28. Manz, N., R. G. Galaske, J. Cho, and J. B. Van Liew. 1986. Analysis of proteins in renal tubule fluid by ultra-microgradient gel electrophoresis in $\mathbf{0 . 5}$ microliter capillary tubes. Electrophoresis. 7:183-187.

29. Tucker, B. J., C. M. Anderson, R. S. Theis, R. C. Collins, and R. C. Blantz.
1992. Glomerular hemodynamics during acute insulin infusion in normal and diabetic rats. Kidney Int. 42:1160-1168.

30. Tucker, B. J., M. M. Mendonca, and R. C. Blantz. 1993. Contrasting effects of acute hyperinsulinemia on renal function in awake non-diabetic and diabetic rats. J. Am. Soc. Nephrol. 3:1686-1693.

31. Myers, B. D. 1988. Diabetes and the kidney. In Cecil's Textbook of Medicine. J. B. Weingarten and L. H. Smith, editors. W. B. Saunders, Philadelphia, PA.

32. Scandling, J. D., and B. D. Myers. 1992. Glomerular size-selectivity and microalbuminuria in early diabetic glomerular disease. Kidney Int. 41:840-846.

33. Anderson, S., and B. M. Brenner. 1988. Pathogenesis of diabetic glomerulopathy: the role of glomerular hyperfiltration. In The Kidney and Hypertension in Diabetes. C. E. Mogensen, editor. Martinus Nijhoff Publishing, Boston, MA. 139-146.

34. Hostetter, T. H. 1990. Pathogenesis of diabetic nephropathy: hemodynamic considerations. Semin. Nephrol. 10:219-227.

35. Abrass, C. K., C. V. Peterson, and G. J. Raugi. 1988. Phenotypic expression of collagen types in mesangial matrix of diabetic and nondiabetic rats. Diabetes. 37:1695-1702.

36. Tilton, R. G., K. Chang, G. Pugliese, D. M. Eades, M. A. Province, W. R. Sherman, C. Kilo, and J. R. Williamson. 1989. Prevention of hemodynamic and vascular albumin filtration changes in diabetic rats by aldose reductase inhibitors. Diabetes. 38:1258-1270.

37. Fioretto, P., R. Trevisan, A. Valerio, A. Avogaro, M. Borsato, A. Doria, A Semplicini, D. Sacerdoti, S. Jones, and E. Bugnetti. 1990. Impaired renal response to a meat meal in insulin-dependent diabetes: role of glucagon and prostaglandins. Am. J. Physiol. 258:F675-F683.

38. Pak, C. H. 1988. Time course and vectorial nature of albumin metabolism in isolated perfused rabbit PCT. Am. J. Physiol. 255:F520-F528.

39. Rasch, R., and C. E. Mogensen. 1980. Urinary excretion of albumin and total protein in normal and streptozotocin diabetic rats. Acta Endocrinol. 95:376381.

40. Mogensen, C. E., C. K. Christensen, and E. Vittinghus. 1983. The stages in diabetic renal disease with emphasis on the stage of incipient diabetic nephropathy. Diabetes. 32(Suppl 2):64-78.

41. Fukui, M. 1991. Altered glomerular mRNA expression of basement membrane components and type 1 collagen in diabetic rats treated with or without insulin therapy. Nippon Jinzo Gakkai Shi. 33:275-281.

42. Tucker, B. J., M. M. Mendonca, E. Scalbert, and R. C. Blantz. 1991. Protective effects of the ACE inhibitor, perindopril, in chronic diabetic rats and prevention of hyperinsulinemia induced renal vasoconstriction. J. Am. Soc. Nephrol. 2:300. (Abstr.)

43. Mogensen, C. E., and K. Solling. 1977. Studies on renal tubular protein reabsorption: partial and near complete inhibition by certain amino acids. Scand. J. Clin. Lab. Invest. 37:477-486. 